\title{
Healthy Eating Index (HEI-2015) of Female College Students According to Obesity and Exercise Participation
}

\author{
Gizem Helvacı ${ }^{1 *}$, Fatma Tayhan Kartal' ${ }^{2}$, Nurcan Yabancı Ayhan ${ }^{1}$ \\ ${ }^{1}$ Department of Nutrition and Dietetics, Faculty of Health Sciences, Ankara University, Ankara; ${ }^{2}$ Department of Nutrition and Dietetics, Faculty of Health Sciences, \\ Çankırı Karatekin University, Çankırı, Turkey
}

Background: Individuals participating in exercise are more likely to lead a healthy lifestyle to achieve their exercise-related goals. This study aimed to examine the differences in dietary quality of female university students by exercise involvement and body mass index (BMI).

Methods: This study was conducted with 360 female university students in Turkey. Students were asked to complete a questionnaire containing general characteristics and food consumption records. The "Healthy Eating Index (HEl-2015)"score was calculated using the results of food consumption records.

Results: The findings showed that the ratio of individuals who exercised regularly was $34.2 \%$. The ratio (44.2\%) of regularly exercising participants with moderate/good diet quality was greater than that of regularly exercising participants with poor diet quality (30.6\%) $(P=0.016)$. There was no significant difference between the scores of overall diet quality according to BMI classification $(P>0.05)$. The score $(45.3 \pm 13.4)$ for overall diet quality of those participating in exercise in the group with normal body weight was higher than the score (41.5土 12.1) for overall diet quality of those not participating in exercise $(P=0.026)$. Those participating in exercise in the group with normal body weight consumed more greens and beans, whole grains, dairy products, seafood/ vegetable proteins, and refined grains than those not participating in exercise $(P<0.05)$.

Conclusion: The rate of overall participation in physical activity was low. However, students participating in physical activity and with a normal body weight had a better diet quality. Creating an ideal environment that encourages students to participate in physical activity at universities can be an effective method for improving their diet quality.

Key words: Exercise, Diet, Obesity
Received February 24, 2021

Reviewed April 26, 2021

Accepted June 7, 2021

*Corresponding author

Gizem Helvacı

(iD)

https://orcid.org/0000-0001-8654-9245

Department of Nutrition and Dietetics, Faculty of Health Sciences, Ankara University, Fatih St. No 197, A Keçiören, Ankara 06290, Turkey

Tel: +90-312-381-2350-6567

Fax: +90-312-381-2355

E-mail: gizemhelvaci_165@hotmail.com

\section{INTRODUCTION}

University students are at a life stage where they start to make their own decisions about their future. Although they possess the biological maturation of an adult individual, their psychosocial development is incomplete. ${ }^{1}$ They often live apart from their families during their education, which can affect adversely their diet quality and lifestyle. The unhealthy habits they can develop during these periods generally persist in their later years. ${ }^{2}$ There are many reasons that students lead an unhealthy lifestyle, such as lack of leisure time, family problems, health status, climatic conditions, and economic situation. ${ }^{3}$ However, interaction between lifestyle behaviors can exist. For example, it is possible that individuals participating in exercise are more careful about having a healthy lifestyle, abstaining from alcohol and smoking, and following a healthier diet. ${ }^{4}$ Recent studies have investigated the relationships between lifestyle factors

Copyright (C) 2021 Korean Society for the Study of Obesity

(ㄷ) This is an Open Access article distributed under the terms of the Creative Commons Attribution Non-Commercial License (https://creativecommons.org/licenses/by-nc/4.o/) which permits unrestricted non-commercial use, distribution, and reproduction in any medium, provided the original work is properly cited. 
in children and adults. Dietary quality has been associated with many factors, such as gender, socio-economic status, and residence. ${ }^{5}$ Recent studies have focused on the relationship between diet quality, regular physical activity, and body mass index (BMI). ${ }^{6,7}$

Regular exercise is defined as a set of planned, structured, and repetitive physical activities carried out with sufficient frequency, duration, and intensity for protection, improvement, and development of health. ${ }^{8}$ It has been reported that regular physical activity improves perceived quality of life and general well-being. ${ }^{9}$ In addition, it is an important tool that empowers an individual's motivation to keep his/her life under control and to achieve his/her liferelated goals. ${ }^{10}$ Many reasons for involvement in exercise have been identified and include stress management, weight management, socialization, improvement of health, and development of strength and endurance. ${ }^{11}$ It is of utmost importance that healthy eating habits and lifestyle as well as regular physical activity are maintained to protect and promote health. The diet model followed, the number of meals, meal frequency, and beverage and food preferences play a role in individuals attaining their exercise-related goals. ${ }^{12}$ Therefore, we hypothesized that individuals participating in exercise would adopt a healthier diet to achieve their exercise-related goals. Healthy Eating Index (HEI) is one of the most utilized measures to assess whether or not a diet is healthy and were last updated in 2015 (HEI2015). ${ }^{13}$ The HEI has been shown to capture diet quality independently of energy intake. ${ }^{14}$ Therefore, it is useful to assess diet quality among populations with different BMI classes and energy intake. This study aimed to examine the differences between female university students' dietary qualities as related to exercise involvement and BMI.

\section{METHODS}

\section{Study design and participants}

A cross-sectional study was conducted on 360 university students studying in Ankara and Çankırı, Turkey. Students were invited to participate in this study using social media and e-mail, and they were informed about this study's objectives and procedures. The students who agreed to participate were invited to the involved institution and asked to complete a short questionnaire, including general characteristics and food consumption records by a face-to-

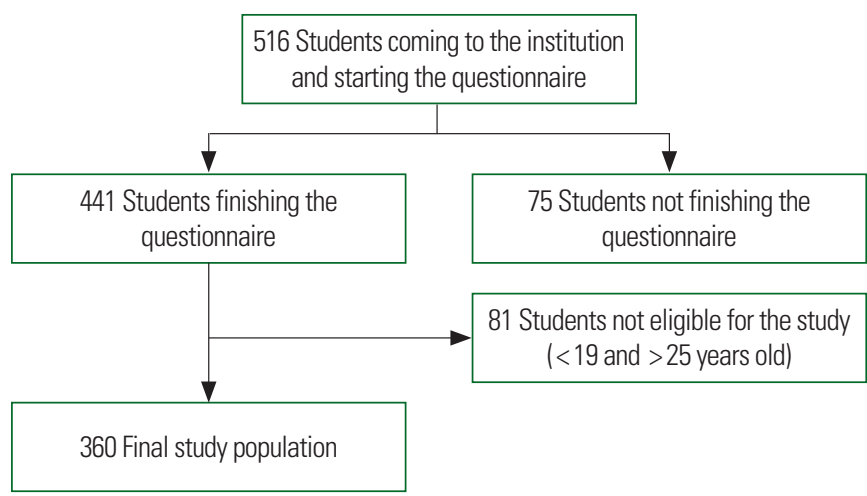

Figure 1. Flowchart of students participating in this study.

face interview method. Female students aged 19-25 years were included in this study, and those who did not complete the questionnaire were excluded. Fig. 1 shows the flowchart diagram of participant selection. The data were collected during the autumn of 2020 . Informed consent was obtained from each student who agreed to participate in this study. This study was conducted in accordance with the Declaration of Helsinki. Ethics committee approval was received from Çankırı Karatekin University (No. 17/07.10.2020).

\section{Food consumption records and HEI-2015}

Food consumption records were obtained from all students using the retrospective 24-hour recall method. All foods and beverages consumed by the students in the past 24 hours were relayed to the researchers and recorded. A "photo catalogue of foods and nutrients" was used to investigate measurements and amounts. ${ }^{15}$ "Standard Recipes" were used to investigate the amount of nutrients in the portions of the foods consumed by the participants. ${ }^{16}$ The average energy and nutritional values of consumed foods were analyzed using a "Nutrition Information Systems" program, which is a food software program in compliance with Turkish food. This software program was suitable for HEI-2015 analysis since it contained data based on the United States Department of Agriculture recommendations.

The HEI-2015 does not reflect diet quantity, but it supplies a score for diet quality. Since it provides for the comparison of scores between BMI groups, a qualitative instead of quantitative approach was selected. The "HEI-2015" score was calculated based on food consumption records. HEI-2015 includes 13 components, nine on dietary adequacy and four on limited consumption of saturated fats, 
refined grains, added sugars, and sodium. A total score of HEI-2015 was obtained by summing the points for each component. The total score was calculated out of 100 , suggesting that, as the score increased, the diet quality improved: 50 points and below, $51-80$ points, and above 80 points reflect poor-, moderate-, and good-diet quality, respectively. ${ }^{17}$ When grouping diet quality in this study, the few good diet quality participants (four) were incorporated into the moderate dietary quality group.

\section{Body mass index}

Body weight and height were recorded by measuring with a portable digital weighing scale and a non-stretching tape measure, respectively. BMI (body weight $[\mathrm{kg}] /$ height $^{2}\left[\mathrm{~m}^{2}\right]$ ) was calculated from body weight and height measurements. Based on BMI, subjects were classified as underweight $\left(\mathrm{BMI}<18.5 \mathrm{~kg} / \mathrm{m}^{2}\right)$, normalweight (BMI $\left.\leq 18.5-24.9 \mathrm{~kg} / \mathrm{m}^{2}\right)$, or overweight/obese (BMI $\left.\geq 25 \mathrm{~kg} / \mathrm{m}^{2}\right) .{ }^{18}$

\section{Regular participation in exercise}

The World Health Organization (WHO) recommends that adults between the ages of 18-64 complete 150 minutes of moderate aerobic exercise or $\geq 75$ minutes of vigorous aerobic exercise each week. ${ }^{19}$ Students who stated that they complied with the physical activity recommendations of $\mathrm{WHO}$ were considered to be completing regular physical activity.

\section{Statistical analysis}

Research data were evaluated using the IBM SPSS ver. 21.0 (IBM Corp., Armonk, NY, USA). Descriptive statistics were used to analyze the general characteristics of the participants. Normality was assessed using the Kolmogorov-Smirnov test. The continuous variables were compared with the t-test or Mann-Whitney U-test according to normality, and the categorical variables were compared with the chi-square test. A chi-square test was used to compare smoking, alcohol use, and regular exercise between BMI groups, as well as BMI classification, smoking, alcohol use, and regular exercise between diet quality groups. To compare BMI means between diet quality groups, the Mann-Whitney U-test was used. Differences between more than two groups were compared with one-way analysis of variance (ANOVA). When comparing energy, macronutri- ents, and diet quality components according to exercise participation between BMI groups, one-way ANOVA was used. Levene's test for equality of variance was used and concluded homogenous variance of the BMI groups. According to these results, pairwise comparisons were performed for total diet quality between BMI groups using post hoc t-tests (Hochberg's GT2). The energy, macronutrients, and diet quality components according to exercise participation for each body weight group were compared using the $t$ test. The level of significance was set at $P<0.05$.

\section{RESULTS}

Table 1 shows the general characteristics of the participants according to BMI classification. The average age of participants was $21.1 \pm 1.7$ years, and the BMI average was $21.6 \pm 3.2 \mathrm{~kg} / \mathrm{m}^{2}$. There was no statistically significant difference in average age according to BMI classification $(P>0.05)$. The findings showed that $13.3 \%$ of participants smoked and $18.1 \%$ used alcohol. The rate of participants who exercised regularly was $34.2 \%$. According to BMI classification, the rates of smoking and alcohol use and the rate of regularly participating in exercise did not exhibit a significant difference $(P>0.05)$.

Table 2 presents the distribution of diet quality of participants

Table 1. General characteristics of the participants according to BMI classification

\begin{tabular}{|c|c|c|c|c|c|}
\hline \multirow[b]{2}{*}{ Variable } & \multirow[b]{2}{*}{$\begin{array}{c}\text { Total } \\
(n=360)\end{array}$} & \multicolumn{3}{|c|}{ BMl classification* } & \multirow[b]{2}{*}{$P$} \\
\hline & & $\begin{array}{l}\text { Underweight } \\
\qquad(\mathrm{n}=60)\end{array}$ & $\begin{array}{c}\text { Normal- } \\
\text { weight } \\
(n=245)\end{array}$ & $\begin{array}{c}\text { Overweight } \\
\text { and obese } \\
(n=55)\end{array}$ & \\
\hline Age (yr) & $21.1 \pm 1.7$ & $20.9 \pm 1.7$ & $21.1 \pm 1.7$ & $21.1 \pm 1.6$ & $0.584^{\dagger}$ \\
\hline BMI $\left(\mathrm{kg} / \mathrm{m}^{2}\right)$ & $21.6 \pm 3.2$ & $17.7 \pm 0.9$ & $21.3 \pm 1.6$ & $27.1 \pm 2.7$ & $<0.001^{\dagger}$ \\
\hline Smoking & & & & & $0.958^{\ddagger}$ \\
\hline Yes & $48(13.3)$ & $8(13.3)$ & $32(13.1)$ & $8(14.5)$ & \\
\hline No & $312(86.7)$ & $52(86.7)$ & $213(86.9)$ & $47(85.5)$ & \\
\hline Alcohol use & & & & & $0.806^{\ddagger}$ \\
\hline Yes & $65(18.1)$ & $12(20)$ & 42 (17.1) & $11(20)$ & \\
\hline No & 295 (81.9) & $48(80)$ & $203(82.9)$ & $44(80)$ & \\
\hline Regular exercise & & & & & $0.732^{\ddagger}$ \\
\hline Yes & 123 (34.2) & $19(31.7)$ & 87 (35.5) & $17(30.9)$ & \\
\hline No & 237 (65.8) & 41 (68.3) & $158(64.5)$ & 38 (69.1) & \\
\hline
\end{tabular}

Values are presented as mean \pm standard deviation or number $(\%)$.

${ }^{*}$ BMl classification: underweight $\left(<18.5 \mathrm{~kg} / \mathrm{m}^{2}\right)$, normal-weight $\left(18.5-24.9 \mathrm{~kg} / \mathrm{m}^{2}\right)$, overweight and obese $\left(\geq 25.0 \mathrm{~kg} / \mathrm{m}^{2}\right)$; Independent sample t-test; ‘Pearson chi-square test.

$\mathrm{BMl}$, body mass index. 
Table 2. Distribution of participants' diet quality according to regular participation in exercise, body mass index, and smoking and alcohol use

\begin{tabular}{|c|c|c|c|c|}
\hline \multirow[b]{2}{*}{ Variable } & \multirow{2}{*}{$\begin{array}{c}\text { Total } \\
(n=360)\end{array}$} & \multicolumn{2}{|c|}{ Diet quality } & \multirow[b]{2}{*}{$P$} \\
\hline & & $\begin{array}{c}\text { Poor } \\
(n=265)\end{array}$ & $\begin{array}{c}\text { Moderate/ } \\
\text { good }(n=95)\end{array}$ & \\
\hline BMI (kg/m²) & $21.6 \pm 3.2$ & $21.4 \pm 3.2$ & $21.9 \pm 3.1$ & $0.153^{*}$ \\
\hline BMI classification & & & & $0.256^{\dagger}$ \\
\hline Underweight $\left(<18.5 \mathrm{~kg} / \mathrm{m}^{2}\right.$ ) & $60(16.7)$ & $49(18.5)$ & $11(11.6)$ & \\
\hline Normal-weight $\left(18.5-24.9 \mathrm{~kg} / \mathrm{m}^{2}\right)$ & $245(68.1)$ & $178(67.2)$ & $67(70.5)$ & \\
\hline Overweight and obese $\left(\geq 25.0 \mathrm{~kg} / \mathrm{m}^{2}\right)$ & $55(15.2)$ & $38(14.3)$ & $17(17.9)$ & \\
\hline Regular exercise & & & & $0.016^{\dagger}$ \\
\hline No & $237(65.8)$ & $184(69.4)$ & $53(55.8)$ & \\
\hline Yes & $123(34.2)$ & $81(30.6)$ & $42(44.2)$ & \\
\hline Smoking & & & & $0.907^{\dagger}$ \\
\hline No & $48(13.3)$ & $35(13.2)$ & $13(13.7)$ & \\
\hline Yes & $312(86.7)$ & 230 (86.8) & $82(86.3)$ & \\
\hline Alcohol Use & & & & $0.675^{\dagger}$ \\
\hline No & $65(18.1)$ & $46(17.4)$ & $19(20.0)$ & \\
\hline Yes & $295(81.9)$ & $219(82.6)$ & $76(80.0)$ & \\
\hline
\end{tabular}

Values are presented as mean \pm standard deviation or number (\%).

*Mann-Whitney U-Test; 'Pearson chi-square test.

$\mathrm{BMI}$, body mass index. according to regular participation in exercise, BMI, and smoking and alcohol use. There was no significant difference in diet quality of participants according to BMI average, BMI classification, and smoking and alcohol use $(P>0.05)$. The rate $(44.2 \%)$ of regularly exercising participants with moderate/good diet quality (44.2\%) was higher than that $(30.6 \%)$ of regularly exercising participants with poor diet quality $(P<0.05)$.

Table 3 presents the energy, macronutrients, and HEI results of participants according to BMI classification and participation in exercise. The energy and macronutrients intake of underweight, normal-weight, and overweight/obese participants did not show a significant difference based on exercise participation. There was no significant difference between the total diet quality scores according to BMI classification of participants $(P>0.05)$. In pairwise comparisons using the post hoc t-test, the total diet quality scores of normal-weight participants were not different from those of underweight and overweight participants $(P=0.83$ and $P=0.67$, re-

Table 3. Healthy Eating Index results of participants according to body mass index classification and participation in exercise

\begin{tabular}{|c|c|c|c|c|c|c|c|c|c|c|c|c|c|}
\hline \multirow[b]{2}{*}{ Variable } & \multicolumn{4}{|c|}{ Underweight $(\mathrm{n}=60)$} & \multicolumn{4}{|c|}{ Normal-weight ( $n=245$ ) } & \multicolumn{4}{|c|}{ Overweight and obese $(n=55)$} & \multirow[b]{2}{*}{$P^{\dagger}$} \\
\hline & Total & $\begin{array}{l}\text { Exercising } \\
\qquad(n=19)\end{array}$ & $\begin{array}{c}\text { Not } \\
\text { exercising } \\
(n=41)\end{array}$ & $P^{*}$ & Total & $\begin{array}{l}\text { Exercising } \\
(n=87)\end{array}$ & $\begin{array}{c}\text { Not } \\
\text { exercising } \\
(n=158)\end{array}$ & $P^{*}$ & Total & $\begin{array}{l}\text { Exercising } \\
\quad(n=17)\end{array}$ & $\begin{array}{c}\text { Not } \\
\text { exercising } \\
(n=38)\end{array}$ & $P^{*}$ & \\
\hline \multicolumn{14}{|l|}{ Energy and nutrients } \\
\hline Energy (kcal) & $1,465 \pm 403$ & $1,395 \pm 454$ & $1,492 \pm 377$ & 0.387 & $1,504 \pm 379$ & $1,522 \pm 406$ & $1,494 \pm 365$ & 0.590 & $1,808 \pm 373$ & $1,784 \pm 297$ & $1,820 \pm 406$ & 0.746 & 0.000 \\
\hline Carbohydrate (g) & $166 \pm 46$ & $153 \pm 53$ & $172 \pm 41$ & 0.130 & $169 \pm 59$ & $169 \pm 65$ & $168 \pm 57$ & 0.903 & $206 \pm 51$ & $203 \pm 54$ & $208 \pm 50$ & 0.774 & 0.000 \\
\hline \multicolumn{14}{|c|}{ Healthy Eating Index-2015 } \\
\hline Total fruits & $1.3 \pm 1.9$ & $1.3 \pm 2.1$ & $1.3 \pm 1.8$ & 0.570 & $1.8 \pm 1.9$ & $1.8 \pm 1.9$ & $1.8 \pm 1.9$ & 0.830 & $1.6 \pm 1.9$ & $1.6 \pm 1.9$ & $1.7 \pm 1.9$ & 0.914 & 0.190 \\
\hline Whole fruits & $1.6 \pm 2.2$ & $1.2 \pm 2.1$ & $1.7 \pm 2.2$ & 0.301 & $2.2 \pm 2.2$ & $2.2 \pm 2.1$ & $2.1 \pm 2.3$ & 0.760 & $2.3 \pm 2.2$ & $2.5 \pm 2.1$ & $2.2 \pm 2.3$ & 0.659 & 0.146 \\
\hline Total vegetables & $2.7 \pm 1.6$ & $3.1 \pm 1.6$ & $2.6 \pm 1.6$ & 0.266 & $2.3 \pm 1.7$ & $2.5 \pm 1.6$ & $2.2 \pm 1.7$ & 0.280 & $2.8 \pm 1.8$ & $2.8 \pm 1.9$ & $2.8 \pm 1.8$ & 0.950 & 0.046 \\
\hline $\begin{array}{l}\text { Seafood and } \\
\text { vegetables protein }\end{array}$ & $1.9 \pm 2.2$ & $2.4 \pm 2.4$ & $1.7 \pm 2.1$ & 0.234 & $2.1 \pm 2.2$ & $2.7 \pm 2.2$ & $1.8 \pm 2.1$ & 0.002 & $2.4 \pm 2.4$ & $2.3 \pm 2.5$ & $2.4 \pm 2.3$ & 0.829 & 0.586 \\
\hline Fatty acid & $2.5 \pm 3.3$ & $2.2 \pm 3.3$ & $2.6 \pm 3.3$ & 0.348 & $2.4 \pm 3.3$ & $1.8 \pm 3.0$ & $2.7 \pm 3.5$ & 0.053 & $2.8 \pm 3.3$ & $2.6 \pm 3.9$ & $2.9 \pm 3.1$ & 0.832 & 0.717 \\
\hline Refined grain & $3.8 \pm 3.6$ & $5.3 \pm 4.0$ & $3.1 \pm 3.3$ & 0.048 & $4.5 \pm 3.9$ & $5.5 \pm 3.9$ & $3.9 \pm 3.9$ & 0.003 & $5.2 \pm 4.2$ & $5.3 \pm 4.6$ & $5.2 \pm 4.1$ & 0.947 & 0.181 \\
\hline Sodium & $3.2 \pm 3.9$ & $2.8 \pm 3.6$ & $3.3 \pm 4.0$ & 0.993 & $2.6 \pm 3.6$ & $2.5 \pm 3.5$ & $2.7 \pm 3.6$ & 0.625 & $1.6 \pm 2.9$ & $0.9 \pm 2.7$ & $1.9 \pm 3.1$ & 0.272 & 0.053 \\
\hline Saturated fat & $3.3 \pm 3.8$ & $1.7 \pm 2.3$ & $4.0 \pm 4.1$ & 0.031 & $3.1 \pm 3.5$ & $2.6 \pm 3.3$ & $3.4 \pm 3.6$ & 0.067 & $3.1 \pm 3.3$ & $1.6 \pm 2.9$ & $3.8 \pm 3.2$ & 0.020 & 0.931 \\
\hline Added sugar & $8.9 \pm 1.8$ & $9.0 \pm 1.8$ & $8.9 \pm 1.7$ & 0.813 & $9.0 \pm 1.7$ & $9.1 \pm 1.7$ & $9.0 \pm 1.8$ & 0.918 & $9.5 \pm 1.0$ & $9.7 \pm 0.8$ & $9.4 \pm 1.1$ & 0.242 & 0.182 \\
\hline Total diet quality & $41.5 \pm 13.1$ & $43.1 \pm 15.1$ & $40.7 \pm 12.2$ & 0.781 & $42.9 \pm 12.7$ & $45.3 \pm 13.4$ & $41.5 \pm 12.1$ & 0.026 & $44.8 \pm 12.4$ & $43.8 \pm 15.5$ & $45.3 \pm 10.9$ & 0.676 & 0.374 \\
\hline
\end{tabular}

Values are presented as mean \pm standard deviation.

${ }^{*}$ Independent sample t-test; ${ }^{\dagger}$ One-way analysis of variance. 
spectively). The total diet quality scores of underweight and overweight/obese participants did not show a statistically significant difference by exercise participation $(P>0.05)$. In the normalweight group, the total score $(45.3 \pm 13.4)$ of diet quality of exercising participants was higher than that $(41.5 \pm 12.1)$ of not exercising participants $(P=0.026)$. In the underweight group, regularly exercising participants consumed more refined grains and less saturated fat than did those not regularly exercising $(P<0.05)$. In the normalweight group, exercising participants consumed more greens and beans, whole grains, dairy products, seafood/vegetable proteins, and refined grains than did those not exercising $(P<0.05)$. In the overweight/obese group, exercising participants consumed less saturated fat than did those not exercising $(P<0.05)$.

\section{DISCUSSION}

Young adulthood is a period of significant lifestyle changes. Individuals in this age group might not have clearly defined their lifestyle. Therefore, encouraging them to partake in healthy behaviors is significant to reduce the risk of disease in the future. It has been reported that individuals in this age group spend more time on sedentary behaviors and do not follow recommendations for physical activity. ${ }^{20}$ The results of this study showed that $34.2 \%$ of female university students regularly participated in physical activity. Other studies in Turkey have reported that the rate of participation in physical activity of female students of $27.8 \%-44.8 \%$ was lower than that of the general population. ${ }^{21,22}$ Sedentary behaviors exhibited by young adults were positively associated with BMI.3 The results of the present study revealed that $16.7 \%$ of the female students were underweight, $15.2 \%$ were overweight/obese, the vast majority (68.1\%) of them had normal body weight, and the mean BMI was $21.6 \pm$ $3.2 \mathrm{~kg} / \mathrm{m}^{2}$. Similarly, Fagaras et al..$^{24}$ reported that the majority of female university students had normal body weight and an average BMI of $20.7 \pm 2.3 \mathrm{~kg} / \mathrm{m}^{2}$. Dayi et al. ${ }^{22}$ reported that the rate of overweight/obese female university students was $34 \%$, which was higher than the rate in our study. The present study showed that $31.7 \%$ of underweight female students, $35.5 \%$ of those with normal body weight, and $30.9 \%$ of overweight/obese students exercised regularly. The lack of difference between participation rates in physical activity according to BMI classification was consistent with the re- sults in the literature. ${ }^{22}$

In this study, the participants' dietary quality was evaluated using the HEI-2015, which is a 13-component measurement tool consistent with dietary recommendations. The total HEI-2015 score of this study was relatively low $(42.9 \pm 12.7)$. The mean overall score among young adults and female college students, as previously estimated using HEI-2015 scores, were $52.8 \pm 14.8$ and $57.6 \pm 14.5$, respectively. ${ }^{25,26}$ There was no difference between the groups with poor and moderate/good diet quality regarding smoking and alcohol use. Some studies have reported that smokers have poorer eating habits than non-smokers. The findings showed that smokers consumed less vegetables, fruits, and fiber; had lower vitamin and mineral intake; and had greater saturated fat intake. ${ }^{27,28}$ These inconsistent results might have been due to the involvement of only female students in the current study, because women generally take care of their health and eat healthier than men. ${ }^{29}$ However, another study of students reported results that were consistent with our results, and the healthy eating habits (intake of vegetables, fruits, milk, and dairy products at the recommended levels) did not change between genders in smoker and non-smoker groups. ${ }^{30}$ Our results revealed that the rate of participants not exercising regularly was higher in the poor diet quality group, while the rate of participants exercising regularly was higher in the moderate/good diet quality group. It has been reported that better diet quality is associated with a higher level of physical activity. ${ }^{31}$ In addition, time spent participating in physical activity is negatively associated with an unhealthy dietary pattern (fast food, snacks). ${ }^{32}$ In this study, the relationship between physical activity level and diet was not investigated. However, an important finding was obtained showing the differences in physical activity participation according to diet quality group.

Many cross-sectional studies have found a relationship between high BMI and low diet quality. ${ }^{6,33}$ On the other hand, McNaughton et al ${ }^{34}$ reported that individuals with high BMI had a better quality of diet, suggesting that this result might arise from false notification. Our results showed similar average BMI levels of the participants with poor and moderate/good diet quality. Moreover, the participants' total scores of diet quality grouped according to BMI class were similar. A study on a similar sample of participants by Arroyo et al. ${ }^{35}$ found that obese and overweight university students had 
lower total scores of diet quality than those with normal body weight. However, it has been reported that obese/overweight and normal body weight female students have similar diet quality levels, which is consistent with our results. ${ }^{35}$ Dietary reporting can be erroneous in individuals whose body weight does not fall into the normal range, which could have affected our results. ${ }^{34}$

In general, being physically active and healthy eating are behaviors that should be evaluated together. ${ }^{36}$ Our results revealed that the dietary quality of those exercising among participants with normal body weight was better than that of those not exercising. However, the dietary quality of underweight and slightly overweight/ obese individuals did not differ according to exercise involvement. The prevalence of disturbed eating behavior was higher in individuals whose body weight did not fall into the normal range. ${ }^{37}$ One of the reasons behind the participation of slightly overweight/obese and underweight individuals in exercise might be eating behavior disorders. ${ }^{38}$ Therefore, interaction between physical activity and diet quality observed in individuals with normal body weight might reflect more realistic results. Our results showed that, among individuals with normal body weight, the amount of seafood/vegetable protein, dairy products, greens and beans, refined grains and whole grains consumed by those exercising was higher than that consumed by those not exercising. Furthermore, the amount of saturated fat consumed by those who were exercising regularly among the underweight and overweight/obese participants was lower than that consumed by those not exercising regularly. The results of a previous study reported that young adult women exercising regularly had higher grain and fruit intake and consumed a lower fat diet than those not exercising. ${ }^{39}$ A study on children and adolescents by Driskell et $\mathrm{al}^{40}$ found a relationship between low vegetable and fruit consumption and low level of physical activity. ${ }^{40}$ Considering the results of this study and the results in the literature, promoting physical activity can be an effective way to make diet choices more healthy and balanced. Thus, it is important to create an environment that encourages students to take part in physical activities at universities. On the other hand, this study did not consider other probable factors affecting diet quality apart from exercising, such as socio-economic status and living alone or with family. This omission might have affected the results of the present study. ${ }^{5}$ To investigate the differences in diet quality, future research should also ex- amine the roles of other lifestyle factors (such as sleep, stress management, social life, peer groups, and sedentary behavior) and their interaction with each other because unveiling the interaction of lifestyle factors can form the basis for interventions aimed to develop healthy habits for individuals.

In this study, the differences in diet quality of young adult university students were examined based on many factors. However, this study had some limitations and strengths. Since this study was cross-sectional, the results might not be generalized to all university students. Information on exercise participation and food consumption records was based on the participants' own statements. Therefore, there might be incomplete or false notifications. In addition, the HEI-2015 score was calculated from the results of one 24-hour recall method, which was a limitation of this study in that it did not represent the usual intake. We did not obtain information about other factors (e.g., sleep and stress) that might have affected diet quality. Despite these limitations, the strengths of this study include body weight and height measured in a large sample size in an objective manner.

\section{CONFLICTS OF INTEREST}

The authors declare no conflict of interest.

\section{ACKNOWLEDGMENTS}

We are grateful to the students for their participation in this study.

\section{AUTHOR CONTRIBUTIONS}

Study concept and design: GH, FTK, and NYA; acquisition of data: GH and FTK; analysis and interpretation of data: $\mathrm{GH}$ and FTK; drafting of the manuscript: GH and FTK; critical revision of the manuscript: GH, FTK, and NYA; statistical analysis: GH and FTK; administrative, technical, or material support: GH, FTK, and NYA; and study supervision: GH, FTK, and NYA.

\section{REFERENCES}

1. Chacón-Cuberos R, Castro-Sánchez M, Muros-Molina JJ, Es- 
pejo-Garcés T, Zurita-Ortega F, Linares-Manrique M. Adherence to Mediterranean diet in university students and its relationship with digital leisure habits. Nutr Hosp 2016;33:405-10.

2. Cervera Burriel F, Serrano Urrea R, Vico García C, Milla Tobarra M, García Meseguer MJ. Food habits and nutritional assessment in a university population. Nutr Hosp 2013;28: 438-46.

3. Biktagirova GF, Kasimova RS. Formation of university students' healthy lifestyle. Int J Environ Sci Educ 2016;11:1159-66.

4. Szabo A, Griffiths MD, Aarhus Høglid R, Demetrovics Z. Drug, nicotine, and alcohol use among exercisers: does substance addiction co-occur with exercise addiction? Addict Behav Rep 2017;7:26-31.

5. Chae W, Ju YJ, Shin J, Jang SI, Park EC. Association between eating behaviour and diet quality: eating alone vs. eating with others. Nutr J 2018;17:117.

6. Pate RR, Taverno Ross SE, Liese AD, Dowda M. Associations among physical activity, diet quality, and weight status in US adults. Med Sci Sports Exerc 2015;47:743-50.

7. Sheldrick MP, Tyler R, Mackintosh KA, Stratton G. Relationship between sedentary time, physical activity and multiple lifestyle factors in children. J Funct Morphol Kinesiol 2018; $3: 15$.

8. Berczik K, Szabó A, Griffiths MD, Kurimay T, Kun B, Urbán R, et al. Exercise addiction: symptoms, diagnosis, epidemiology, and etiology. Subst Use Misuse 2012;47:403-17.

9. Huang H, Humphreys BR. Sports participation and happiness: evidence from US microdata. J Econ Psychol 2012;33:776-93.

10. Archer T, Garcia D. Physical exercise influences academic performance and well-being in children and adolescents. Int J Sch Cogn Psychol 2014;1:e102.

11. Kilpatrick M, Hebert E, Bartholomew J. College students' motivation for physical activity: differentiating men's and women's motives for sport participation and exercise. J Am Coll Health 2005;54:87-94.

12. Dinç N, Gökmen MH, Ergin E. Investigating the dietary habits of the individuals who regularly exercise. Natl J Sport Sci 2017;1:43-53.

13. Krebs-Smith SM, Pannucci TE, Subar AF, Kirkpatrick SI, Lerman JL, Tooze JA, et al. Update of the Healthy Eating Index:
HEI-2015. J Acad Nutr Diet 2018;118:1591-602.

14. Reedy J, Lerman JL, Krebs-Smith SM, Kirkpatrick SI, Pannucci TE, Wilson MM, et al. Evaluation of the Healthy Eating Index-2015. J Acad Nutr Diet 2018;118:1622-33.

15. Rakıcıoğlu N, Acar Tek N, Ayaz A, Pekcan G. Yemek ve besin fotoğraf kataloğu [Photo catalog of foods and nutrients: measures and amounts]. Ankara: Ata Ofset Yayınevi; 2012.

16. Merdol Kutluay T. Toplu beslenme yapılan kurumlar için standart yemek tarifeleri [Standard meal recipes for institutions with collective nutrition]. Ankara: Hatipoğlu Yayınevi; 2003.

17. Basiotis PP, Carlson A, Gerrior SA, Juan WY, Lino M. Healthy eating index: 1999-2000. Washington (DC): Center for Nutrition Policy and Promotion, US Department Of Agriculture; 2002.

18. World Health Organization. Obesity: preventing and managing the global epidemic: report of a WHO consultation. Singapore: World Health Organization; 2000.

19. World Health Organization. Global recommendations on physical activity for health. Geneva: World Health Organization; 2010.

20. Clemente FM, Nikolaidis PT, Martins FM, Mendes RS. Physical activity patterns in university students: do they follow the public health guidelines? PLoS One 2016;11:e0152516.

21. Arslan SA, Daşkapan A, Çakır B. Specification of nutritional and physical activity habits of university students. TAF Prev Med Bull 2016;15:171-80.

22. Dayi A, Acikgoz A, Guvendi G, Bayrak L, Ersoy B, Gur C, et al. Determination of factors affecting physical activity status of university students on a health sciences campus. Med Sci Monit 2017;23:325-34.

23. Peterson NE, Sirard JR, Kulbok PA, DeBoer MD, Erickson JM. Sedentary behavior and physical activity of young adult university students. Res Nurs Health 2018;41:30-8.

24. Fagaras SP, Radu LE, Vanvu G. The level of physical activity of university students. Procedia Soc Behav Sci 2015;197: 1454-7.

25. Faught EL, McLaren L, Kirkpatrick SI, Hammond D, Minaker LM, Olstad DL. Socioeconomic disadvantage across the life course is associated with diet quality in young adulthood. Nutrients 2019;11:242. 
26. Dhillon J, Diaz Rios LK, Aldaz KJ, De La Cruz N, Vu E, Asad Asghar S, et al. We don't have a lot of healthy options: food environment perceptions of first-year, minority college students attending a food desert campus. Nutrients 2019;11:816.

27. Northrop-Clewes CA, Thurnham DI. Monitoring micronutrients in cigarette smokers. Clin Chim Acta 2007;377:14-38.

28. Palaniappan U, Jacobs Starkey L, O’Loughlin J, Gray-Donald $\mathrm{K}$. Fruit and vegetable consumption is lower and saturated fat intake is higher among Canadians reporting smoking. J Nutr 2001;131:1952-8.

29. Imamura F, Micha R, Khatibzadeh S, Fahimi S, Shi P, Powles J, et al. Dietary quality among men and women in 187 countries in 1990 and 2010: a systematic assessment. Lancet Glob Health 2015;3:e132-42.

30. Wilson DB, Smith BN, Speizer IS, Bean MK, Mitchell KS, Uguy LS, et al. Differences in food intake and exercise by smoking status in adolescents. Prev Med 2005;40:872-9.

31. Storey KE, Forbes LE, Fraser SN, Spence JC, Plotnikoff RC, Raine $\mathrm{KD}$, et al. Diet quality, nutrition and physical activity among adolescents: the Web-SPAN (Web-Survey of Physical Activity and Nutrition) project. Public Health Nutr 2009;12: 2009-17.

32. Uusi-Ranta N. The Association of diet and physical activity in nairobian pre-adolescents. Helsinki: Helsingin Yliopisto; 2020.

33. Whitton C, Ma Y, Bastian AC, Fen Chan M, Chew L. Fast- food consumers in Singapore: demographic profile, diet quality and weight status. Public Health Nutr 2014;17:1805-13.

34. McNaughton SA, Ball K, Crawford D, Mishra GD. An index of diet and eating patterns is a valid measure of diet quality in an Australian population. J Nutr 2008;138:86-93.

35. Arroyo Izaga M, Rocandio Pablo AM, Ansotegui Alday L, Pascual Apalauza E, Salces Beti I, Rebato Ochoa E. Diet quality, overweight and obesity in university students. Nutr Hosp 2006;21:673-9.

36. Jayawardene WP, Torabi MR, Lohrmann DK. Exercise in young adulthood with simultaneous and future changes in fruit and vegetable intake. J Am Coll Nutr 2016;35:59-67.

37. Duncan AE, Ziobrowski HN, Nicol G. The prevalence of past 12-month and lifetime DSM-IV eating disorders by BMI category in US men and women. Eur Eat Disord Rev 2017; 25:165-71.

38. Mathisen TF, Bratland-Sanda S, Rosenvinge JH, Friborg O, Pettersen G, Vrabel KA, et al. Treatment effects on compulsive exercise and physical activity in eating disorders. J Eat Disord 2018;6:43.

39. Georgiou C, Betts N, Hoos T, Glenn M. Young adult exercisers and nonexercisers differ in food attitudes, perceived dietary changes, and food choices. Int J Sport Nutr 1996;6:402-13.

40. Driskell MM, Dyment S, Mauriello L, Castle P, Sherman K. Relationships among multiple behaviors for childhood and adolescent obesity prevention. Prev Med 2008;46:209-15. 